\title{
Otras economías, otros espacios, otros retos para la Geografía Económica ${ }^{1}$
}

\author{
José Luis Sánchez Hernández \\ Universidad de Salamanca
}

La reflexión sobre el futuro de la investigación en Geografía Económica puede desarrollarse a partir de la definición misma de la disciplina. En un texto anterior (Sánchez, 2003), he propuesto definir la Geografía Económica como el estudio de la concreción desigual y diferenciada de la actividad económica en el territorio. En otras palabras, la Geografía Económica se afana por comprender, primero, cómo y por qué las actividades económicas se distribuyen de forma desequilibrada en el territorio y, segundo, cómo y por qué los agentes económicos operan de forma territorialmente distinta. La combinación contingente de ambas tendencias estructurales en cada territorio concreto (de escala local, regional, nacional) genera un paisaje o espacio económico diverso y también cambiante en el tiempo. Las corrientes o escuelas de pensamiento más actuales en Geografía Económica, como el enfoque relacional (Bathelt \& Glückler 2011) o el evolucionista (Boschma \& Martin eds. 2010), examinan esa concreción con herramientas conceptuales y metodológicas específicas. Por su parte, los grandes temas de interés actual que distinguen Barnes y Christhopers (2018: 42), a saber, las geografías del capitalismo, las geografías de las empresas, las geografías de la localización y las geografías económicas alternativas, desentrañan las particularidades de dicha concreción en procesos económicos determinados que implican interacciones entre todas las escalas geográficas, desde la global a la más puramente local.

En todo caso, y desde cualquier perspectiva teórica o preocupación temática, reflexionar sobre el futuro de la investigación en Geografía Económica requiere una reconsideración de las dos categorías básicas de la definición propuesta: la economía y el territorio. ¿Qué entendemos hoy por economía? ¿En qué territorios actúan actuamos- los agentes económicos para satisfacer nuestras necesidades? El resto de esta intervención se dedica a avanzar algunas ideas sobre ambas cuestiones, para terminar sintetizando los desafíos que plantean a la Geografía Económica unas nociones ampliadas de economía y de territorio como las que siguen a continuación y que, conviene aclararlo, están elaboradas desde una óptica básicamente española.

\section{REPENSANDO LA ECONOMÍA, OTRA VEZ}

Desde la aportación de Gibson-Graham (2008), al menos, la Geografía Económica es consciente de que la economía es un proceso social de satisfacción de las necesidades humanas mucho más amplio y diverso que el limitado conjunto de actores que operan en el mercado y de relaciones que se establecen su seno a través de un precio fijado en condiciones más o menos competitivas. Como quiera que la Geografía Económica española se ha dedicado, casi exclusivamente, al análisis de actividades de este tipo, se dibujan aquí dos potenciales líneas de trabajo que, sin ser del todo novedosas, han recibido muy escasa atención hasta el momento.

En primer término, el estudio de la profundísima reestructuración registrada en el sector público, que ha pasado de regirse por una lógica más o menos distributiva a adoptar condiciones de competencia que, en determinados ámbitos, generan pingües beneficios. Es el caso de los sectores productivos que se han liberalizado en

${ }^{1}$ Este texto se encuadra en el proyecto de investigación "Espacios y prácticas económicas alternativas para la construcción de la resiliencia en las ciudades españolas" (20162018). Programa Estatal de Investigación, Desarrollo e Innovación Orientada a los Retos de la Sociedad - financiado por el Ministerio de Economía, Industria y Competitividad y por el Fondo Europeo de Desarrollo Regional (FEDER), referencia CSO2015-65452-R (MINECO/FEDER). Este proyecto participa en la Red de Excelencia "Retos para las ciudades del siglo XXI: una agenda de investigación para la construcción de espacios urbanos sostenibles e innovadores" (junio de 2017 - junio de 2019 ). Plan Estatal de Fomento de la Investigación Científica y Técnica de Excelencia 2013-2016, referencia CSO2016-81718-REDT. 
las últimas décadas tras la disolución de los monopolios estatales requerida por el ingreso en la Unión Europea, caso de la distribución de agua y energía o del transporte aéreo y ferroviario. No sabemos mucho sobre las estrategias espaciales de las compañías que distribuyen agua, energía, personas y mercancías por el territorio español y lo conectan con el exterior. Una geografía económica de grandes corporaciones como lberia, Renfe, Repsol, ENDESA, Iberdrola, o de conglomerados como Ferrovial, ACS o Eulen, todos ellos estrechamente dependientes de la regulación y/o el presupuesto de las Administraciones Públicas, generaría un conocimiento tan atractivo para la Academia como útil a la Sociedad que la sustenta.

En esta misma línea hay que subrayar la necesidad de considerar la vertiente espacial de otras actividades económicas formales, pero no destinadas a la venta, como los servicios públicos. La persistente denuncia genérica de los efectos demoledores de las políticas de austeridad sobre el modesto Estado del bienestar español tampoco ha venido acompañada de una indagación cuidadosa sobre la reestructuración espacial de la oferta de los servicios públicos fundamentales; el estudio de Hamnet (2014) sobre el Reino Unido puede servir como punto de partida para un apasionante programa de investigación en España. En particular, conviene dedicar un esfuerzo riguroso y sostenido a una cuestión largamente debatida como es la de la paulatina penetración de la lógica del mercado -y la competencia- en los servicios públicos que todavía permanecen en manos del Estado (educación, sanidad, asistencia social), al menos en la mayor parte de sus respectivos campos de actuación.

El caso de la enseñanza universitaria es suficientemente ilustrativo del impacto que tiene la introducción de la competencia como principio parcialmente orientador (al menos, y de momento) en una actividad tradicionalmente ajena al escrutinio del mercado. Es bien conocido el efecto que la economía de la prescripción tiene en actividades concretas como la alta cocina o el mundo del vino. La publicación periódica de guías (Michelin, Parker) que ensalzan unos locales o productos y relegan otros puede decidir el destino económico no sólo de determinadas empresas, sino también de los territorios donde actúan y que generan los recursos tangibles e intangibles que comercializan esas compañías. La normalización y estandarización de las condiciones de acceso a y promoción en la carrera científico-universitaria se traduce en el envío masivo de artículos a las revistas con factores de impacto más elevados, mientras las menos citadas languidecen con frecuencia por falta de originales y terminan por desaparecer o caer en el más triste de los olvidos.

Del mismo modo empiezan a actuar los tan traídos y llevados ranking de universidades. Originarios de contextos culturales muy distintos, celosos de la libre competencia y de la minimización de la intervención pública en la vida social y económica, su llegada a la Europa meridional no será neutral desde una perspectiva geográfica. Siguiendo la lógica del mercado, las universidades mejor calificadas en los ranking reciben más fondos del sector privado (becas a estudiantes con talento, financiación de investigaciones, donaciones de antiguos alumnos) e incluso de gobiernos de países en desarrollo que buscan una formación de excelencia para sus élites. Cuando los gobiernos autonómicos en España se plantean distribuir sus presupuestos entre las universidades de su región conforme a contratos-programa vinculados a la consecución de ciertos objetivos, se está introduciendo también una lógica de competencia en el sistema universitario que tiene, sin duda, algunos efectos positivos en un entorno regulatorio con frecuencia ayuno de estímulos, pero cuyas consecuencias territoriales a largo plazo deben ser analizadas con detenimiento. La definición de la calidad de una universidad conforme a estos criterios competitivos (por ejemplo, la llamada "empleabilidad" de sus titulados) puede estar detrás de la burbuja de universidades privadas que se especializan, precisamente, en la oferta de estudios muy cotizados en el mercado laboral y pueden exhibir altas tasas de inserción profesional en comparación con otros centros públicos que portan la pesada carga de enseñar saberes anticuados o inútiles. Tampoco se sabe mucho, por cierto, sobre los actores que impulsan estas universidades privadas y los patrones geográficos que guían sus decisiones de inversión. Desconozco ahora si desde otras disciplinas se han elaborado estudios concretos, pero desde luego los geógrafos económicos en España no hemos analizado la relación entre los factores territoriales y los resultados de las universidades medidos en términos de estudiantes, publicaciones, financiación... ni el impacto que la economía de la prescripción tiene sobre dicha relación. ¿Cuál es la capacidad de una universidad mal financiada en una región o provincia poco desarrollada para competir con centros bien calificados y localizados en regiones ricas, con presupuestos públicos mejor dotados y un tejido económico intensivo en conocimiento? ¿Qué consecuencias traerá la competencia interuniversitaria sobre ciudades medias con universidades poco especializadas que se fundaron por razones distributivas?

Lamentablemente, no es la enseñanza universitaria la única actividad económica de servicio público afectada por la extensión de la lógica del mercado y la competencia de una forma, además, territorialmente diferenciada. También la sanidad y la asistencia social, por ejemplo a personas mayores o dependientes, se ha convertido en un mercado donde operan grupos privados de dimensión creciente cuya lógica espacial está todavía por desvelar- 
se. A la par, la percepción popular de que esos mismos servicios se prestan por el sector público con una dotación de recursos muy desigual entre las regiones españolas es confirmada por algunos informes especializados (García y otros. 2018) que ponen de relieve unas formas de desigualdad e injusticia social y espacial que tampoco se han tenido en consideración desde la Geografía Económica.

A la vez que trata la transformación, parcial pero patente, de determinados servicios públicos en mercados crecientemente sujetos a la competencia, la Geografía Económica española de los próximos años debería también tomar en consideración las modalidades de coordinación económica que se reclaman ajenas, distintas o contrarias al capitalismo convencional centrado en la búsqueda del beneficio personal, en la empresa privada como unidad básica de organización de la producción, en el mercado competitivo como espacio de interacción y en la relación salarial como vía principal de acceso personal a las rentas.

La primera de todas esas formas distintas de coordinación económica es la economía doméstica, de la reproducción y de los cuidados, que es la base imprescindible de toda forma de sociedad humana, sea capitalista o no. En el hogar se hace patente la existencia y sostenibilidad de otras formas no retribuidas ni lucrativas de coordinación económica, como el altruismo, la redistribución y la reciprocidad (recuérdese aquí el imprescindible texto de Karl Polanyi La Gran Transformación, 1944). La economía feminista lleva muchos años reivindicando la centralidad de la esfera doméstica en el entramado socioeconómico y denunciando con fuerza, una vez más, su mercantilización a manos de la expansión social de las relaciones capitalistas, que está generando tensiones y desigualdades entre quienes pueden pagar en el mercado por los servicios de cuidados (del hogar, de niños, de ancianos, de enfermos) y quienes no pueden hacerlo. Se trata de una tensión especialmente lacerante porque los estudios de White y Williams (2012, entre otros muchos) en el Reino Unido demuestran una preferencia mayoritaria por cubrir los cuidados a través de relaciones comunitarias con familiares, amigos y vecinos, y no mediante la contratación impersonal de servicios o suministros externos. Según dichos autores, esa preferencia explicaría el hecho de que hasta el $44 \%$ del tiempo sea dedicado a trabajo doméstico no remunerado en los países avanzados, cifra que contradice la tesis de que vivimos en una sociedad exclusivamente regida por las relaciones mercantilizadas. Existe aquí, pues, un punto de confrontación entre percepción y realidad, entre deseo y posibilidad, que merece una lectura geográfica, ya que los trabajos de estos autores apuntan a diferencias territoriales apreciables en el continuo autoabastecimiento-externalización de la economía de los cuidados.

Este apego social hacia soluciones económicas no competitivas ni lucrativas se manifiesta también en la persistencia de lo que Gibson-Graham (2008) denominaron economías comunitarias y otros autores califican como prácticas económicas alternativas (Conill y otros 2012). Bancos de tiempo, huertos urbanos, grupos de consumo, monedas sociales, mercados de productores, talleres Do It Yourself, repair cafés, junto con fórmulas más complejas como la banca ética, el comercio justo, las cooperativas integrales, la agricultura ecológica o las criptomonedas, comparten la visión de que otra economía es posible (Castells y otros, 2017). Estas prácticas económicas alternativas se componen de pequeñas comunidades que practican una democracia directa, comparten las tareas de manera equitativa, excluyen el lucro de sus objetivos y manifiestan un profundo respeto por la naturaleza en todos los órdenes de su actividad productiva (Sánchez 2017). Recientemente, se ha puesto en marcha un proyecto de investigación en España dedicado al estudio del funcionamiento interno y el impacto económico de estas prácticas en algunas ciudades españolas (PRESECAL [en línea]). Con todo, hace falta una labor más sostenida en el tiempo y más extensiva en el espacio para evaluar la auténtica magnitud del fenómeno de las economías alternativas y, sobre todo, su capacidad para construir esa economía diferente, más humana, democrática y sostenible que resulta tan atractiva en el discurso como difusa en la realidad concreta.

Particular interés reviste la investigación sobre la relación entre estas formas de coordinación económica horizontal y el capitalismo global contemporáneo. La agricultura ecológica comenzó como un movimiento extravagante, pero hoy todos los supermercados ofrecen comida bio, eco, orgánica... Lo que fueron propuestas puramente colaborativas y desinteresadas como AirBnB o Uber se han convertido, gracias a las posibilidades de las plataformas digitales, en negocios sumamente lucrativos cuyas externalidades negativas se proyectan en el espacio urbano de mucha ciudades. Del mismo modo, el proyecto MARES, promovido en Madrid por el gobierno municipal surgido de las elecciones de 2015 y una serie de colectivos ciudadanos involucrados en distintas modalidades de economía comunitaria, recibe financiación de la Unión Europea, habitualmente denostada como avalista de las políticas de austeridad. El debate sobre el riesgo de convencionalización de las economías comunitarias y su posible cooptación por parte del sistema capitalista y el Estado, entendido en sentido amplio, permanece abierto y corresponde a los geógrafos indagar sobre las diversas formas en que se resuelve esa tensión en territorios con trayectorias económicas, sociales y políticas específicas. 


\section{OTROS ESPACIOS ECONÓMICOS}

Tras apuntar la conveniencia de examinar la concreción desigual y diferenciada de una serie de actividades económicas en el territorio, es preciso advertir que los espacios donde actúan los agentes económicos también han cambiado en los últimos años. La Geografía Económica debe ahora ocuparse de dos espacios económicos no convencionales que interactúan entre sí y a la vez se complementan con el espacio público donde se desenvuelve la vida económica más tangible: se trata del hogar y el ciberespacio.

El hogar no es solamente la sede de la economía de los cuidados, sino también un espacio significativo para el desarrollo de un número creciente de actividades económicas muy dependientes de las tecnologías digitales y de la creatividad, así como de otras sumergidas en la precariedad y la marginalidad. ¿Cuántas empresas comienzan su andadura en un domicilio particular, como ilustra la monografía colectiva de Mason y otros (2016)? ¿Cuánto trabajo intelectual se efectúa en el hogar? ¿Qué ha sido del teletrabajo, una de las primeras esperanzas y temáticas surgidas tras la difusión de Internet? Sabemos que las TIC han extendido el horario -y con él, el espacio - de trabajo hasta el punto de que en Francia acaba de aprobarse el derecho del trabajador a no contestar correos electrónicos fuera de la jornada laboral. Pero la desmaterialización de numerosas tareas productivas hace muy difícil ya deslindar con nitidez el trabajo ordinario en espacios convencionales del que se efectúa en otros espacios frecuentados por el trabajador, incluyendo aquí el desplazamiento en trenes o aviones, y las consiguientes esperas en estaciones o aeropuertos. Tampoco tenemos claro si la impresión en 3D va a propiciar un retorno a los hogares de algunas actividades productivas y un consiguiente rediseño de las ciudades y de las cadenas de valor, como sugiere la monografía coordinada por Nawratek ed. (2017).

En el otro extremo, el ciberespacio todavía no ha despertado el interés de la Geografía Económica española, aunque ya hay trabajos estupendos basados en big data, como los del grupo de investigación t-GIS [en línea] dirigido por Javier Gutiérrez Puebla. La geografía física del ciberespacio español (redes de cableado, nodos de conexión, ubicación de los centros de almacenamiento de datos) y la gestión del tráfico de datos (volumen de flujos, tarifas asociadas, empresas operadoras) son asuntos poco conocidos. La indagación sobre esta interfaz ciberespacio-espacio extenso no se debe limitar, en todo caso, a la escala nacional, dado que la red tiene dimensiones mundiales a través del cableado submarino y los satélites de comunicaciones, cuya gestión neutral está precisamente en cuestión en estos tiempos.

Ahora bien, también la interfaz ciberespacio-hogar encierra temas de interés geográfico. Las implicaciones de la generación de infinidad de datos en nuestra vida cotidiana ya fueron teorizadas por Echeverría (1994) en su Telépolis, donde define el telesegundo como una mercancía que los espectadores producimos gratuitamente cuando vemos un programa de televisión y que las cadenas televisivas revenden a las empresas de publicidad. El hogar, pues, no es solamente un espacio de los cuidados o un espacio productivo no convencional, sino también un yacimiento de riqueza -en forma de datos- explotada por toda clase de compañías. Ahora bien, habrá que considerar con detalle la distribución regional y local de esa riqueza digital y las posibles desigualdades territoriales en la oferta de bienes y servicios que las empresas produzcan en función de la rentabilidad esperada de cada hogar, barrio, ciudad o región.

El comercio electrónico es otro nexo entre el hogar y el ciberespacio con profundas implicaciones geográficas por su efecto directo sobre la actividad logística y sobre el despliegue espacial del comercio minorista tradicional. El célebre problema de la última milla sigue sin resolverse -probablemente porque es insoluble- y aparecen nuevas fórmulas como el reparto con drones, en bicicleta o, quizá pronto, mediante automóviles autónomos. Como toda forma de comercio, el comercio electrónico (y sus implicaciones en otras ramas de la economía, en el mercado de trabajo y en la reconfiguración de la ciudad) es un proceso netamente geográfico al que tampoco se ha atendido debidamente en España, pese a la rápida penetración de esta forma de distribución en los años más recientes.

Finalmente, toda investigación sobre los espacios económicos, en su versión más clásica o en esta formulación extendida, debería ir acompañada de una meta-reflexión sobre la posición relativa de cada uno de ellos en el paisaje económico global. Desde el artículo clásico de Inmaculada Caravaca (1998), la Geografía Económica española está habituada a identificar y caracterizar los espacios ganadores y emergentes. Esa labor de síntesis requiere una actualización periódica que la misma autora ya ha intentado recientemente (Caravaca, 2017) y que debe acompañarse de una atención no menor a los espacios perdedores y rezagados, en la línea propuesta por Rodríguez-Pose (2018) para relacionar la trayectoria económica de los territorios y la irrupción de partidos políticos de dudosas convicciones democráticas. 


\section{HACIENDO GEOGRAFÍA ECONÓMICA}

Ante una economía más compleja que se desenvuelve en espacios económicos más diversos, la Geografía Económica española se enfrenta a varios retos disciplinares si quiere seguir siendo fiel a la definición propuesta al comienzo de este texto, con independencia del marco teórico que adoptemos sus practicantes o de la cuestión empírica que se procure iluminar en cada investigación concreta.

Primero, hay que manejar nuevas fuentes de información, como big data y los conjuntos de datos abiertos que ofrecen las administraciones más comprometidas con la transparencia y la ciudadanía. Pero las técnicas cualitativas tradicionales (entrevistas, observación de campo, grupos de discusión...) seguirán siendo imprescindibles para estudiar los hogares, las economías alternativas o las estrategias de las grandes compañías, entre otros temas sobre los que falta información estadística sistematizada. Esta esquizofrenia metodológica nos obligará a conocer el manejo de aplicaciones informáticas muy dispares con el fin de almacenar los datos, organizarlos, extraer sus múltiples significados y después elaborar representaciones carto-gráficas expresivas y, a ser posible, explicativas en sí mismas.

Por eso, en segundo lugar, será cada vez más difícil trabajar de forma individual; ya lo es, en realidad, si reparamos en el decreciente número de publicaciones firmadas por una sola persona. Incluso los grupos de investigación pequeños y mono-disciplinares -típicos de la Geografía Económica española- experimentan ya notables complicaciones para dominar las competencias teóricas, metodológicas e instrumentales que requiere la investigación puntera. La participación en marcos interdisciplinares y la constitución de extensas redes de investigación integradas por nodos locales más o menos especializados en ciertos temas y técnicas se impondrá como fórmula organizativa habitual, al estilo de la RETURBAN [en línea] que funciona en España desde 2017.

Tercero, y último. Las dos constataciones precedentes no son inocuas para el desempeño cotidiano de nuestra investigación. Quienes sentimos pasión por la Geografía Económica sufriremos -más todavía- la desagradable sensación de llegar tarde a todos los temas, o de no saber lo suficiente sobre tantas líneas de investigación cruciales como caben en el seno de nuestra querida disciplina. Y esa desazón se verá acrecentada por la imperiosa necesidad de dedicar una fracción creciente de nuestro tiempo -el bien más preciado por su naturaleza finita- a la coordinación de personas, actividades y recursos, en detrimento de la lectura reposada, de la reflexión calmada y de la escritura sosegada. Sólo las ganas de saber más Geografía Económica nos mantendrán activos, mientras el cuerpo aguante.

\section{BIBLIOGRAFÍA}

BARNES, T.J. \& CHRISTOPHERS, B. (2018). Economic Geography: a Critical Introduction. Oxford: Wiley-Blackwell.

BATHELT, H. \& GLÜCKLER, J. (2011). The Relational Economy. Geographies of Knowing and Learning. Oxford: Oxford University Press.

BOSCHMA, R.A. \& MARTIN, R. eds. (2010). The Handbook of Evolutionary Economic Geography. Chentelham: Edward Elgar.

CARAVACA BARROSO, I. (1998). Los nuevos espacios emergentes. Revista de Estudios Regionales, 50, 39-80.

CARAVACA BARROSO, (2017). Globalización neoliberal y crisis en los espacios ganadores y emergentes. Ciudad y Territorio Estudios Territoriales, $\quad$ 194, 613-628.

CASTELLS, M. y otros (2017). Otra economía es posible. Cultura y economía en tiempos de crisis. Madrid: Alianza Editorial.

CONILL, J. y otros (2012). Otra vida es posible: prácticas económicas alternativas durante la crisis. Barcelona: Editorial UOC.

ECHEVERRÍA, J. (1994). Telépolis. Barcelona: Destino.

GARCÍA, G.; BARRIGA, L. RAMÍREZ, J.M., ZUBIRÍA, A., VELASCO, L. \& IZQUIERDO, A. (2018). Índice DEC - Índice de Desarrollo de los Servicios Sociales 2017. Asociación Estatal de Directoras y Gerentes en Servicios Sociales.

GIBSON-GRAHAM, J.K. (2008). Diverse Economies: Performative Practices of 'Other Worlds'. Progress in Human Geography, 32, 613-632.

HAMNETT, CH. (2014). Shrinking the Welfare State: the Structure, Geography and Impact of British Government Benefit Cuts. Transactions of the Institute of British Geographers, 39, 490-503.

MASON, C., REUSCHKE, D., SYRETT, S. \& VAN HAM, M. eds. (2016). Entrepreneurship in Cities: Neighbourhoods, Households and Homes. Northampton: Edward Elgar.

NAWRATEK, K. ed. (2017). Urban re-industrialization. Goleta (CA): Punctum Books. 
POLANYI, K. (1944). La gran transformación. Los orígenes políticos y económicos de nuestro tiempo. México: Fondo de Cultura Económica (edición de 2003).

PRESECAL <en línea> Espacios y prácticas económicas alternativas para la construcción de la resiliencia en las ciudades españolas. URL: https://www.researchgate.net/project/Espacios-y-practicas-economicas-alternativas-para-la-construccion-dela-resiliencia-en-las-ciudades-espanolas-IP-Jose-Luis-Sanchez-Hernandez

RETURBAN <en línea> Red de Grupos de Investigación sobre conocimientos, técnicas y experiencias innovadoras para desarrollar y gestionar espacios urbanos sostenibles y resilientes, desde una perspectiva económica, espacial y social. URL: Www.returban.com

RODRÍGUEZ-POSE, A. (2018). The revenge of places that don't matter (and what to do about it). Cambridge Journal of Regions, Economy and Society, 11, 189-209.

SÁNCHEZ HERNÁNDEZ, J.L. (2003). Naturaleza, localización y sociedad. Tres enfoques para la Geografía Económica. Salamanca: Ediciones Universidad de Salamanca.

SÁNCHEZ HERNÁNDEZ, J.L. (2017). Las prácticas económicas alternativas en perspectiva geográfica. Salamanca: Ediciones Universidad de Salamanca (edición institucional).

t-GIS - Transporte, Infraestructura y Territorio <en línea>: https://www.ucm.es/tgis

WHITE, R.J. Y WILLIAMS, C.C. (2012). The Pervasive Nature of Heterodox Economic Spaces at a Time of Neoliberal Crisis: towards a "Postneoliberal" Anarchist Future. Antipode, 44, 1625-1644. 